$H$ ypochaeris radicata $\mathrm{L}$. es un miembro de la familia más diversa de las angiospermas, las Asteraceae (Turner, 1997). Esta familia se caracteriza por presentar flores agrupadas en cabezuelas sostenidas por brácteas involucrales, cáliz ausente o modificado (vilano), corolas simpétalas, estambres singenésicos, dos carpelos sincárpicos, ovario ínfero y un solo óvulo de placentación basal (Rzedowski, 1978; Cabrera-Rodríguez y Villaseñor, 1987; Cronquist, 1989; Villaseñor, 1993; Judd et al., 2002). H. radicata pertenece a la tribu Lactuceae, la cual está constituida por plantas laticíferas con cabezuelas liguladas, i.e. todas las flores son hermafroditas y funcionales, con la corola alargada y plana (lígula), y con el ápice dividido en cinco lóbulos.

De acuerdo con Spencer (1978), el género Hypochaeris L. contiene 100 especies distribuidas en Europa, Asia, la región mediterránea y en América del Sur. Sus números cromosómicos base son: $x=3,4,5,6,7$ y 8 . En este género son frecuentes los fenómenos de poliploidía y el polen es equinolofado. A partir de extractos no saponificables de polen de $H$. radicata se ha obtenido polinastanol; además, sus lígulas contienen varios tipos de carotenoides (González, 1978).

Datos sobre la distribución, la morfología y las condiciones ambientales de esta especie en México, así como su origen, han sido recabados con detalle (Vibrans, 2005). Vibrans (1996) informó por primera vez sobre la presencia de este taxón en el territorio mexicano, con base en ejemplares recolectados en La Marquesa, municipio de Ocoyoacac, estado de México, y según Villaseñor y Espinosa-García (1998), hasta la fecha sólo se conocía en esa localidad.

En exploraciones botánicas realizadas en la Sierra del Ajusco, en el Distrito Federal (México), se detec-

\title{
Nota SOBRe La PRESEnCIA DE HypOChaERIS RADICATA L. (Asteraceae: LactuCEAE) EN LA Flora del Distrito Federal, MÉXICO
}

\author{
Oscar Hinojosa-Estinosa ${ }^{1,2}$ y Ramiro CRUz-Durán ${ }^{1}$ \\ 'Herbario de la Facultad de Ciencias (FCME), Universidad Nacional Autónoma de \\ México. Apartado Postal 70-399, México 04510, D.F., México. \\ ${ }_{2}^{2}$ Autor para correspondencia. Correo-e: oapostat@yahoo.com.mx
}

tó la presencia de $H$. radicata como planta ruderal. Luego de examinar los datos de colecta de ejemplares de esta especie depositados en el Herbario Nacional (MEXU) se llegó a la conclusión de que este hallazgo representa el segundo registro de esta especie en la flora mexicana y el primero para el Distrito Federal.

En la zona $H$. radicata se presenta como una hierba perenne de 29 a 67 $\mathrm{cm}$ de alto, con raíces axonomorfas; el tallo está poco o nada ramificado y es erecto, delgado, ligeramente surcado, fistuloso y con látex. Las hojas están dispuestas en roseta basal, de 4.5 a 18.5 $\mathrm{cm}$ de largo y 0.7 a $4.5 \mathrm{~cm}$ de ancho, rara vez en el tallo, pero cuando es así se presentan brácteas; las láminas son simples, los ápices redondeados, rara vez agudos, y los márgenes dentados a pinnatilobados; la superficie adaxial presenta indumento hirsuto, con una vena principal. Las cabezuelas son homógamas, liguladas, terminales y solitarias, de (1.3-) 2.8 a $3.8 \mathrm{~cm}$ de diámetro en la floración; el pedúnculo es similar al tallo, de (3.6-) 8 a 26 (-30.3) $\mathrm{cm}$ de largo, está provisto de brácteas lanceoladas de (1.2-) 2 a $3(-3.8) \mathrm{mm}$ de largo, y de color púrpura oscuro en el ápice; el involucro es cilíndrico a sub- campanulado, de (6-) 10 a 13 (-15) $\mathrm{mm}$ de alto, graduado, con 3 ó 4 series de filarios herbáceos, verdosos, glabros o con indumento puberulento o hirsuto; sus márgenes son hialinos, ciliados y sus ápices son de color púrpura oscuro y presentan una cresta conspicua, redondeados y fimbriados; la serie más externa es lanceolada a ovada, las más internas son lanceoladas. El receptáculo es plano a convexo, cicatricoso al dispersarse las cipselas, provisto de páleas angostas, acuminadas, escariosas y deciduas. Las flores son todas liguladas, hermafroditas y fértiles, la lámina de la lígula de (7.2) 9 a 11 (-14) $\mathrm{mm}$ de largo, su ápice con cinco lóbulos triangular-ovados; la parte adaxial es amarilla y la parte abaxial es verdosa-púrpura o gris-púrpura, excepto en los márgenes; éstos son amarillos y la base del tubo es pilosa. Las anteras son cinco, de (3-) 4 a 4.5 (-5.2) $\mathrm{mm}$ de longitud, con apéndices apicales ovados, hialinos, de (0.3-) $0.4(-0.5) \mathrm{mm}$ de longitud y las bases conspicuamente sagitadas, hialinas, de $0.3(-0.5) \mathrm{mm}$ de longitud. El estilo es hispiduloso, amarillo, dividido en dos ramas de 0.8 a $1.2(-1.3) \mathrm{mm}$ de longitud, bifurcadas, papilosas y obtusas en el ápice. Las cipselas son angostamente elípti- 


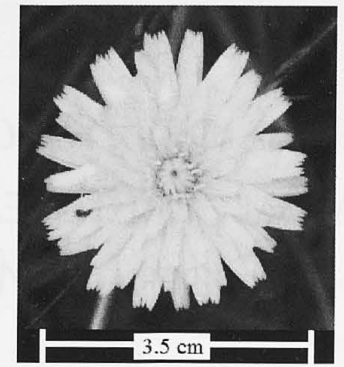

a

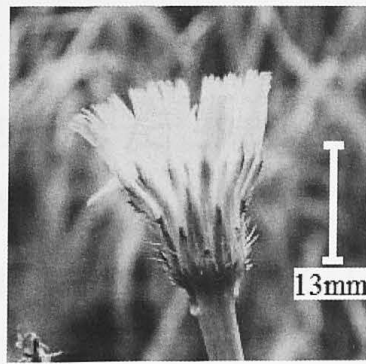

b

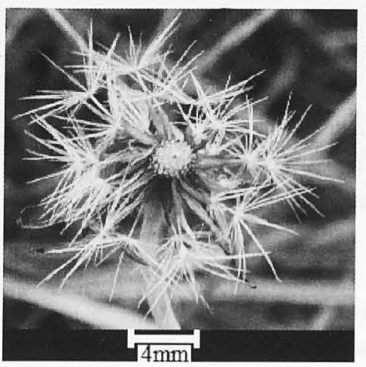

C

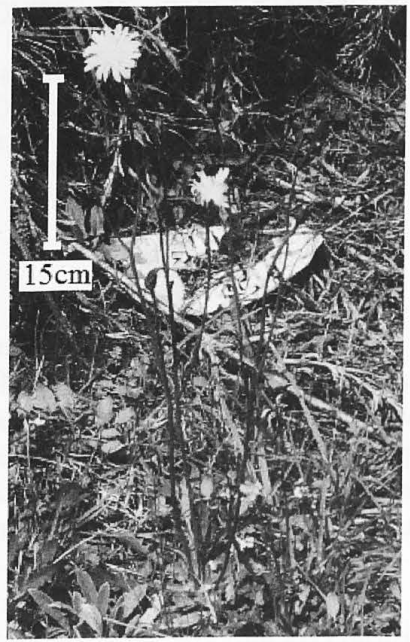

d

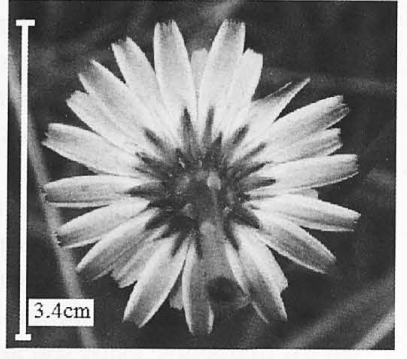

e

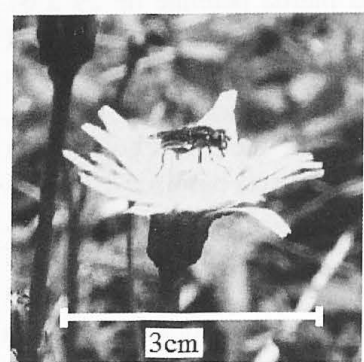

f

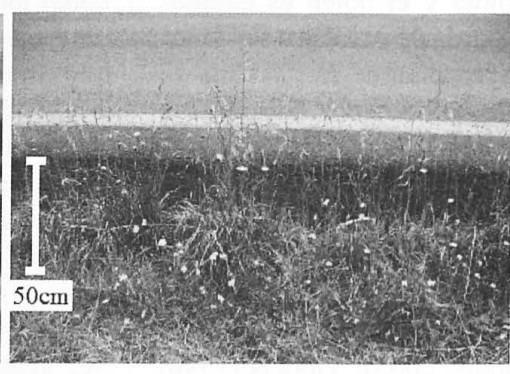

g

Figura 1. Hypochaeris radicata L. a. Cabezuela ligulada. b. Involucro. c. Receptáculo y cipselas con vilano. d. Planta completa. e. Parte abaxial de la cabezuela. f. Díptero visitando cabezuela. g. Población.

cas en contorno, surcado-espiculadas, glabras, de color marrón-violeta en la madurez, de 4 a $5.5 \mathrm{~mm}$ de largo; el ápice se prolonga en un pico delgado, espiculado, de (2.1-) 5 a 8 (-9) $\mathrm{mm}$ de longitud, donde se asienta el vilano de cerdas capilares, pilosas, desiguales en longitud, de 2 a $10 \mathrm{~mm}$ (figura 1).

$H$. radicata fue encontrada a las orillas de la carretera Picacho-Ajusco, en áreas sombreadas y soleadas de bosque de pino, a una altitud de $2560 \mathrm{~m}$ s.n.m., asociada a Pinus patula Schltdl. et Cham., P. hartwegii Lindl., Taraxacum officinale F.H.Wigg., Ribes affine Kunth, Achillea millefolium L., Geranium seemannii Peyr, Penstemon roseus (Cerv. ex Sweet) G.Don, 
Hypoxis mexicana Schult. et Schult. f., Crataegus mexicana Moc. et Sessé ex DC., Buddleia parviflora Kunth., B. cordata Kunth., Prunus serotina Ehrh., Muhlenbergia macroura (Kunth) Hitchc., Commelina orchioides Booth ex Lindl. y Cheilanthes sp.

Las características de la zona en donde se encontró a $H$. radicata son muy similares a las que se mencionan en la página electrónica de malezas de México de la CONABIO (Vibrans, 2005) y a las señaladas por Vibrans (1996): bosque de pino-encino, altitud 2600-3020 m y área perturbada (orilla de autopista y de vía de ferrocarril). Por ello, cabría esperar que esta especie continúe expandiéndose prima-riamente en regiones adyacentes favorables para su establecimiento, esto es, en áreas ruderales de bosque de pino o pino-encino, como la zona de la carretera federal a Cuernavaca, las inmediaciones de Amecameca, la región de Tepeapulco e incluso la Sierra de Pachuca.

H. radicata tiene una apariencia similar a $T$. officinale, con la cual podría llegar a confundirse; sin embargo, se diferencia de esta última por presentar lígulas de color verde-púrpura o grispúrpura en la parte abaxial, filarios con el ápice púrpura oscuro provisto de una cresta, vilano de cerdas capilares pilosas, desiguales en longitud, recep- táculo paleáceo, pedúnculos con brácteas y hojas con indumento hirsuto en la parte adaxial. Asimismo, H. radicata se distingue de Picris echioides L. (especie ruderal que se encontró en la carretera Picacho-Ajusco, cerca de las poblaciones de $H$. radicata) por la ausencia de espinas y el receptáculo paleáceo.

\section{EJEMPLARES EXAMINADOS:}

MÉXICO: Distrito Federal, Delegación Tlalpan, Los Palomares, 11 km al SE de la ciudad de México, carretera Picacho-Ajusco, 19¹4'42.8' N, 99¹4'37.1" O, 2 agosto 2007 (flor), Oscar Hinojosa Espinosa 112, 113 (FCME, MEXU); 12 agosto 2007 (flor, fruto), Oscar Hinojosa Espinosa 114 (FCME, MEXU).

\section{Literatura citada}

Cabrera-Rodríguez L. y Villaseñor J.L. 1987. Revisión bibliográfica sobre el conocimiento de la familia Compositae en México. Biotica 12:131-147.

Cronquist A. 1989. An Integrated System of Clasification of Flowering Plants. Columbia University Press, Nueva York.

González A.G. 1977. Lactuceae - chemical review. En: Heywood V.H., Harborne J.B. y Turner B.L. Eds. Biology and Chemistry of the Compositae II, pp. 1081-1095, Academic Press, Londres.

Judd W.S., Campbell C.S., Kellogg E.A., Stevens P.F. y Donoghue M.J. 2002.
Plant Systematics: a Phylogenetic Approach. 2a ed., Sinauer, Sunderland, Massachussetts.

Rzedowski J. 1978. Claves para la identificación de los géneros de la familia Compositae en México. Acta Cientifica Potosina 7:1-145.

Spencer A.T. 1977. Lactuceae - systematic review. En: Heywood, V.H., Harborne J.B. y Turner B.L. Eds. Biology and Chemistry of the Compositae II, pp. 1067-1079, Academic Press, Londres.

Turner B.L. 1997. The Comps of Mexico. A systematic account of the family Asteraceae. Vol. I Eupatorieae. Phytologia Memoirs 11:1-272.

Vibrans H. 1996. Notes on neophytes 2. New records for Asteraceae from the center of Mexico. Phytologia 81:369381.

Vibrans H. 2005. Malezas de México. En línea:

<www.conabio.gob.mx/malezasde mexico/2inicio/home-malezas-mexico. htm>

Villaseñor J.L. y Espinosa-García F.J. 1998. Catálogo de Malezas de México. Fondo de Cultura Económica. México, D.F.

Villaseñor J.L. 1993. La familia Asteraceae en México. Revista de la Sociedad Mexicana de Historia Natural. Vol. Esp. (XLIV): 117-124.

Recibido: 18 de septiembre de 2007 Aceptado: 13 de diciembre de 2007 